\title{
Hepatic Steatosis Alleviated in Diabetic Mice upon Dietary Exposure to Fibroin via Transgenic Rice: Potential STAMP2 Involvement in Hepatocytes
}

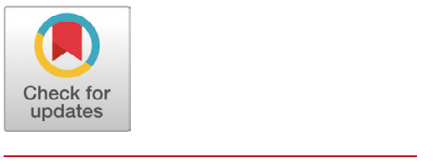

Received: August 20, 2020

Revised: September 9, 2020

Accepted: September 20, 2020

${ }^{\dagger}$ Corresponding author Jong-Min Kim

Dept. of Anatomy and Cell Biology,

College of Medicine, Dong-A University,

Busan 49201, Korea.

Tel: +82-51-240-2792

Fax: +82-51-245-3872

E-mail:jmkim7@dau.ac.kr

Copyright ๑ 2020 The Korean Society of Developmental Biology.

This is an Open Access article distributed under the terms of the Creative Commons Attribution Non-Commercial License (http://creativecommons.org/licenses/ by-nc/4.0/) which permits unrestricted non-commercial use, distribution, and reproduction in any medium, provided the original work is properly cited.

ORCID

Ji-Eun Park

https://orcid.org/0000-0001-5110-0501

Yeon Jae Jeong

https://orcid.org/0000-0002-9693-2907

Hye Young Kim

https://orcid.org/0000-0002-8487-3655

Young Hyun Yoo

https://orcid.org/0000-0002-6809-6737

Kwang Sik Lee

https://orcid.org/0000-0001-5446-276X

Won Tae Yang

https://orcid.org/0000-0003-1912-4874

Doh Hoon Kim

https://orcid.org/0000-0002-5409-0027

Jong-Min Kim

https://orcid.org/0000-0002-6201-1739

Conflict of interests

The authors declare no potential conflict of interest.

\author{
Ji-Eun Park', Yeon Jae Jeong ${ }^{1}$, Hye Young Kim', Young Hyun Yoo' , Kwang Sik Lee², \\ Won Tae Yang ${ }^{2}$, Doh Hoon Kim², and 'Jong-Min Kim' \\ 'Dept. of Anatomy and Cell Biology, College of Medicine, Dong-A University, Busan 49201, Korea \\ ${ }^{2}$ College of Life Sciences and Natural Resources, Dong-A University, Busan 49315, Korea
}

\section{Abstract}

Many benefits of silk protein fibroin (SPF) have been suggested in biomedical applications; and notably, significant SPF effects have been observed for metabolic syndromes that are directly linked to insulin resistance, such as type 2 diabetes mellitus (T2DM). Based on our previous findings, we believe that SPF from spiders exhibits outstanding glucose-lowering effects in diabetic BKS.Cg-m+/+Lepr ${ }^{\mathrm{db}}$ mice. In order to evaluate the dietary effects of SPF in diabetic animals, we generated several lines of transgenic rice (TR) that expresses SPF, and the feeding of TR-SPF to diabetic animals decreased blood glucose levels, but did not change insulin levels. Western blot analyses of hepatic proteins showed that AMP-activated protein kinase (AMPK) expression and phosphorylation both decreased in TR-SPF-fed groups, compared with controls. This finding suggests that the glucose-lowering effects in this diabetic animal model might be AMPK-independent. In contrast, six-transmembrane protein of prostate 2 (STAMP2) was upregulated after TR-SPF exposure. Together with STAMP2, the Akt protein phosphorylation increased after TR-SPF exposure, which indicates that STAMP2 leads to Akt phosphorylation and thus increases insulin sensitivity in hepatocytes. Importantly, the hepatic steatosis that was seen in the liver of diabetic mice was remarkably alleviated in TR-SPF-fed mice. Hepatocytes that were immunopositive for STAMP2 were overwhelmingly observed in hepatic tissues from TR-SPF-fed mice compared to the control. Taken together, these results suggest that feeding diabetic mice with TR-SPF upregulates STAMP2 expression and increases Akt phosphorylation in hepatic tissues and thus potentially alleviates insulin resistance and hepatic steatosis.

Keywords: Spider silk protein fibroin, Six-transmembrane protein of prostate 2 (STAMP2), Hepatocytes, Hepatic steatosis, Diabetic mouse

\section{INTRODUCTION}

Diabetes mellitus $(\mathrm{DM})$ is a metabolic syndrome that is classified into two types: type $1 \mathrm{DM}$ (T1DM) and type 2 DM (T2DM) (Thomas \& Philipson, 2015). While T1DM is linked with 
Acknowledgements

This study was supported by a grant from the Next-Generation BioGreen 21 Program (Project No. PJ013684022020), Rural Development

Administration, Korea.

Authors' contributions

Conceptualization: Lee KS, Yang WT, Kim DH, Kim JM.

Data curation: Park JE, Jeong YJ.

Formal analysis: Park JE.

Methodology: Park JE, Jeong YJ, Lee KS, Yang WT. Validation: Park JE, Kim HY, Yoo YH, Kim JM.

Investigation: Kim DH, Kim JM.

Writing - original draft: Park JE.

Writing - review \& editing: Kim JM.

Ethics approval

All procedures were performed in accordance with protocols approved by the Dong-A

University Animal Care and Use Committee (DIACUC-19-13). failure in insulin production by pancreatic $\beta$-cells, T2DM is characterized by insulin resistance. Insulin resistance is generally identified as an impaired response to insulin stimulation of the liver, muscle, and adipose tissue. Insulin resistance causes glucose disposal and subsequently results in a compensatory increase in $\beta$-cell insulin production (Deacon, 2019). The metabolic consequences of insulin resistance can cause hyperglycemia, hypertension, dyslipidemia, visceral adiposity, and hyperuricemia (Lebovitz, 2001; Freeman \& Pennings, 2020). Thus, progression of insulin resistance can provoke metabolic syndromes, nonalcoholic fatty liver disease (NAFLD), and T2DM. Therefore, most T2DM medications have been developed to enhance insulin sensitivity. At present, metformin, a derivative of galegine (a natural product from the plant Galega officinalis), is the most representative therapeutic drug for T2DM (Sanchez-Rangel \& Inzucchi, 2017). Metformin functions by activating one of the enzymes involved in gluconeogenesis, known as 5-adenosine monophosphate-activated protein kinase (AMPK) (Rena et al., 2017).

Silk protein fibroin (SPF) from spiders has been suggested as a useful biomaterial for industrial and medical purposes (Altman et al., 2003; Kluge et al., 2008). The biological effects of SPF include enhancement of glucose and lipid metabolism (Hyun et al., 2004; Jung et al., 2010; Do et al., 2012), anti-viral activity (Gotoh et al., 2000), DNA damage protection (Park et al., 2002), and blood pressure-depressing activity (Igarashi et al., 2006). Recombinant spider SFP exhibits non-cytotoxic and non-inflammatory effects in NIH 3T3 cells (Lee et al., 2016) and reduces blood glucose levels in diabetic mice (Lee et al., 2014; Park et al., 2019). Recently, we demonstrated that dietary exposure to transgenic rice (TR) that expresses spider SPF reduces blood glucose levels, possibly through the potential mediating role of insulin receptor substrated-1 phosphorylation in adipocytes (Park et al., 2019). However, the fundamental mechanism(s) by which TR-SPF lowers blood glucose levels in diabetic mice remains to be elucidated in hepatic tissues.

In the present study, TR-SPF was fed to diabetic BKS.Cg-m+/+Lepr ${ }^{\mathrm{db}}$ mice, changes in glucose and insulin levels were monitored in blood, and alterations in proteins associated with insulin signaling and insulin resistance were analyzed in hepatic tissues. The purpose of this study was to determine whether specific proteins related to insulin resistance in hepatocytes correlate with changes in blood glucose levels in TR-SPF-fed mice.

\section{MATERIALS AND METHODS}

\section{Reagents and antibodies}

Bouin's solution, eosin and hematoxylin were purchased from Sigma Chemical (St. Louis, MO, USA). The western enhanced chemiluminescence (ECL) detection reagent was purchased from Bio-Rad (Hercules, CA, USA). VECTASTAIN ${ }^{\circledR}$ Elite ABC Kit was from Vector Laboratories (Burlingame, CA, USA). Anti-AMPK $\alpha$, Phospo-AMPK $\alpha$ (Thr172), Akt and Phosphor-Akt (Ser473) antibodies were purchased from Cell Signaling Technology (Danvers, MA, USA). AntiSTEAP4 (six-transmembrane protein of prostate 2, STAMP2) antibody was from Proteintech (Rosemont, IL, USA). Anti- $\beta$-Tubulin antibody was from Sigma Chemical (St. Louis, MO, USA).

\section{Production of transgenic rice}

cDNAs encoding a partial repetitive region and the C-terminal domain of $A v M a S p$ (Lee et al., 2012) were PCR-amplified from $p G E M T-A v M a S p$ using the forward primer 5'-GGATCCATGGCCGCCGCAGCCGCA-3' (with BamHI) and reverse primer 5'-GTCGACTAACGCTGCGGCAGAGGC-3' (with SaI). The AvMaSp fragment was inserted 
into the binary pPZP-3'PINII-Bar vector ( $p$ AvMaSp-Bar) containing the seed-specific GluC promoter and the Tnos terminator sequence. To generate TR containing the partial AvMaSp gene, pAvMaSp-Bar was introduced into Agrobacterium tumefaciens (EHA105) by electroporation. A modified version of a general rice transformation protocol was used (ToKi, 1997; Mohanty et al., 1999). Rice grains were prepared using a rice milling machine and processed to a fine powder using a blender for oral administration. The compositions of both control (Dong-jin rice) and TR powders were the same, including equal proportions of casein, sucrose, corn oil, cellulose, vitamin mixture, mineral mixture, choline bitartrate, DL-methionine, and t-butylhydroquinone.

\section{Animals and sampling}

Diabetic male BKS.Cg-m+/+Lepr ${ }^{\mathrm{db}}$ mice (8 weeks of age) were purchased from Samtako Bio-Korea (Osan, Korea). The mice were housed in a climate-controlled $\left(21 \pm 2^{\circ} \mathrm{C}\right)$ animal room at a constant 12-h light/dark cycle. All procedures were performed in accordance with protocols approved by the Dong-A University Animal Care and Use Committee (DIACUC-19-13). Each control or TR powder was provided in a separate feeding container ad libitum once per day. After 4 weeks of feeding, the mice ( $\mathrm{n}=15$ per group) were sacrificed by carbon dioxide asphyxiation and whole blood was collected by cardiac puncture. The hepatic tissue samples were finely dissected and immediately used for the protein analysis and histological study.

\section{Determination of blood glucose and insulin levels}

Plasma glucose levels were measured in tail blood using a GlucoDr Blood Glucose Test Strip (Hasuco, Seoul, Korea). Serum insulin concentrations were determined by mouse insulin enzymelinked immunosorbent assay (ELISA) kit (Fujifilm Wako Shibayagi, Gunma,Japan).

\section{Western blot analysis}

Small pieces of abdominal adipose tissues were homogenized in lysis buffer $[300 \mathrm{mM} \mathrm{NaCl}$, 0.5\% Triton X-100, $50 \mathrm{mM}$ Tris- $\mathrm{HCl}\left(\mathrm{pH}\right.$ 7.4), $25 \mathrm{mM} \mathrm{NaF}, 1 \mathrm{mM} \mathrm{Na}_{3} \mathrm{VO}_{4}, 10 \mathrm{mMNa}_{4} \mathrm{P}_{2} \mathrm{O}_{7}$, and protease inhibitor] for $40 \mathrm{~min}$ on ice. The lysates were centrifuged at $13,000 \times \mathrm{g}$ at $4{ }^{\circ} \mathrm{C}$ for 20 min, the supernatants were collected and protein concentration was measured using the BCA protein assay kit. $30 \mu \mathrm{g}$ of protein extract with sodium dodecyl sulfate (SDS)-loading buffer was electrophoretically separated on a 8\%-15\% gradient SDS-PAGE gel, and transferred onto a nitrocellulose membrane. The membranes were blocked with $5 \%$ non-fat dry milk dissolved in Trisbuffered saline (TBS) buffer containing $0.05 \%$ Tween-20 at RT for $1 \mathrm{~h}$. The blots were incubated with primary antibodies, followed by incubation with appropriate HRP-conjugated secondary antibodies. The signals were detected with ECL detection reagent in the LAS-4000 (Fuji, Tokyo, Japan). $\beta$-Tubulin was used as internal control for total cellular proteins.

\section{Immunohistochemistry}

Hepatic tissues were fixed in Bouin's solution, embedded in paraffin, and sectioned at $5 \mu \mathrm{m}$ thickness. Tissue sections were placed on glass slides, deparaffinized, hydrated, and treated with $1 \%$ hydrogen peroxide $\left(\mathrm{H}_{2} \mathrm{O}_{2}\right)$ for 10 min to suppress endogenous peroxidase activity. Antigen retrieval was performed by heating the sections in $1 \mathrm{mM}$ citric acid solution ( $\mathrm{pH}$ 6.0). Sections were incubated with the primary antibody for STAMP2 at $4{ }^{\circ} \mathrm{C}$ overnight and reacted with biotinylated horse anti-mouse IgG for $1 \mathrm{~h}$ at RT, as per the manufacturer's instructions for Vectastain Elite $\mathrm{ABC}$ kit. The stained sections were developed with liquid diaminobenzidine and counterstained with hematoxylin. The results were observed using a ScanScope digital slide scanning system (Aperio Technologies, Vista, CA, USA). 


\section{Statistics}

Data were expressed as the mean $\pm \mathrm{SD}$ of at least 3 independent experiments. The difference in means between 2 groups was analyzed using the Student's $t$-test. Mean values were considered significantly different at $p<0.05$.

\section{RESULTS AND DISCUSSION}

We have previously demonstrated that TR-SPF is effective in reducing blood glucose levels in diabetic mice and that concurrent lipolysis in abdominal adipocytes is particularly associated with increased insulin receptor substrate-1 (IRS1) expression and phosphorylation (Park et al., 2019). However, the underlying mechanism by which TR-SPF lowers blood glucose levels in diabetic mice remains to be elucidated at the hepatic level. In this context, we investigated whether feeding diabetic mice TR-SPF causes histopathological changes in their hepatic tissues, as well as alterations in their protein levels, and whether they correlate with insulin resistance in hepatocytes.

In the diabetic mouse model (BKS.Cg-m+/+Lepr ${ }^{\mathrm{db}}$ mice) that was employed, blood glucose levels significantly reduced after exposure to TR-SPF compared with that of the control (Fig. 1a), while serum insulin levels remained unaltered (Fig. 1b). This indicates that dietary exposure to TRSPF in these diabetic mice only caused a reduction in glucose levels, without significant alterations

\section{a}

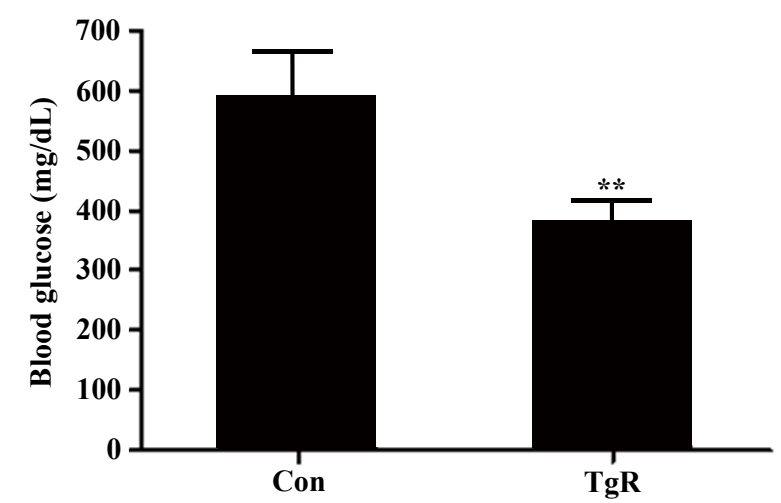

b



Fig. 1. Changes in blood glucose levels (a) and serum insulin concentrations (b) after feeding diabetic mice TR-SPF for 4 weeks. The data are expressed as mean $\pm S D$ of three independent experiments performed in triplicates. ${ }^{* *} p<0.01$ compared with those of control (CON). TgR denotes TR-SPF-fed group. TR, transgenic rice; SPF, silk protein fibroin. 
in serum insulin levels. Thus, it is presumed that TR-SPF might be rather effective to the target tissues for insulin (i.e., the liver and/or adipose tissues) in this animal model.

Recently, silk fibroin (Park et al., 2020), silk protein hydrolyzate (Do et al., 2012), and silk peptides (Park et al., 2020) have been suggested to exert potential antidiabetic effects in diabetic mice $\left(\mathrm{C} 57 \mathrm{BL} / \mathrm{KsJ}-L e p r^{\text {db/da }}\right)$ and non-obese type 2 diabetic rats through the regeneration of pancreatic $\beta$-cells, an increase in pancreatic $\beta$ cell mass, and a potentiation of insulin secretion, respectively. Therefore, it is believed that the effect or target of fibroin or silk proteins could differ depending on either diabetic animal models or routes (or methods) of administration to the animals.

In the present study, hepatic histopathology showed that dietary exposure to TR-SPF significantly alleviated hepatic steatosis (Fig. 2). The hepatocytes in the liver of BKS.Cg-m+/+Lepr ${ }^{\mathrm{db}}$ mice mostly retained several lipid droplets in their cytoplasm (Fig. 2a and 2c). However, TR-SPF exposure obviously resulted in disappearance of the cytoplasmic lipid droplets in the hepatocytes (Fig. $2 \mathrm{~b}$ and $2 \mathrm{~d}$ ), and this indicated that dietary exposure to TR-SPF can provoke a restoration of normal hepatocytes from steatotic hepatocytes. This effect of TR-SPF is comparable to that of metformin, a widely used first-line antidiabetic drug. Metformin is known to ameliorate lipid accumulation in the liver in hepatic steatosis (Woo et al., 2014; Song et al., 2015). The therapeutic effects of metformin are mediated by the activation of AMPK (Hawley et al., 2002; Shaw et al., 2005). In this context, we first monitored the changes in AMPK levels and its phosphorylation in hepatic tissues. However, both AMPK protein content and phosphorylation were consistently downregulated after exposure to TR-SPF (Fig. 3). These results indicate that TR-SPF decreases blood glucose levels and alleviates hepatic steatosis in this animal model through an AMPK-independent pathway.

Next, we sought to identify a possible mediator for TR-SPF action and investigated the sixtransmembrane protein of prostate 2 (STAMP2) as a potential molecule associated with the alleviation of hepatic steatosis. Previously, it has been shown that STAMP family proteins are associated with adipocyte differentiation (Sikkeland \& Saatcioglu, 2013). Furthermore, STAMP2 expression is elevated in fed mice compared to fasting mice (Wellen et al., 2007). Recently, Kim


Fig. 2. Change in hepatic histology after feeding diabetic mice TR-SPF for 4 weeks. Hematoxylin-eosin $(H /$ E) staining. Original magnifications scanned by digital slide system: low mag. (100x) and high mag. (400x). Con and TgR denote control ( $a$ and $c$ ) and TR-SPF-fed group ( $b$ and $d$ ), respectively. Arrows indicate lipid droplets in hepatocytes. TR, Transgenic rice; SPF, silk protein fibroin. 




Fig. 3. Alterations in the levels of AMPK, pAMPK (Thr172), STAMP2, Akt, and pAkt (Ser473) proteins in hepatic tissues after feeding diabetic mice TR-SPF for 4 weeks. SDS-PAGE followed by western blotting was performed using $25 \mu \mathrm{g}$ of protein lysates from hepatic tissues. $\beta$-Tubulin was used as an internal control for all cellular proteins. AMPK, AMP-activated protein kinase; STAMP2, sixtransmembrane protein of prostate 2; TR, transgenic rice; SPF, silk protein fibroin; SDS, sodium dodecyl sulfate.

et al. (2015) revealed that hepatic STAMP2 plays an important role in preventing high fat diet (HFD)-induced NAFLD and that STAMP2 overexpression improves hepatic steatosis and insulin resistance in NAFLD. In this study, STAMP2 protein expression was consistently upregulated by TR-SPF exposure (Fig. 3), and STAMP2 upregulation was accompanied by increased Akt phosphorylation (Fig. 3). STAMP2 is known to target the Akt signaling pathway in human adipocytes (Cheng et al., 2011), and it has been reported that administration of antibodies against STAMP2 decreases Akt phosphorylation (Qin et al., 2011). The changes in STAMP2 proteins were confirmed in hepatic tissues using immunohistochemical localization (Fig. 4). Notably, hepatocytes that were immune-positive for STAMP2 were more evident in hepatic tissues from TR-SPF-fed mice (Fig. 4b) compared to the control (Fig. 4a). Furthermore, the STAMP2 proteins were mostly localized in the membrane or boundary of hepatocytes (Fig. 4b). This observation was also consistent with that of a previous study (Korkmaz et al., 2005).

Taken together, this study showed that feeding diabetic mice TR-SPF causes upregulation of STAMP2 expression in hepatic tissues, and thus, alleviates hepatic steatosis. However, it also suggested that AMPK activation may not be required for this cellular process to occur in diabetic mice. We believe that these findings should be confirmed in the other animal models that are used for diabetic research. Finally, the underlying mechanism by which TR-SPF is able to relieve hepatic 

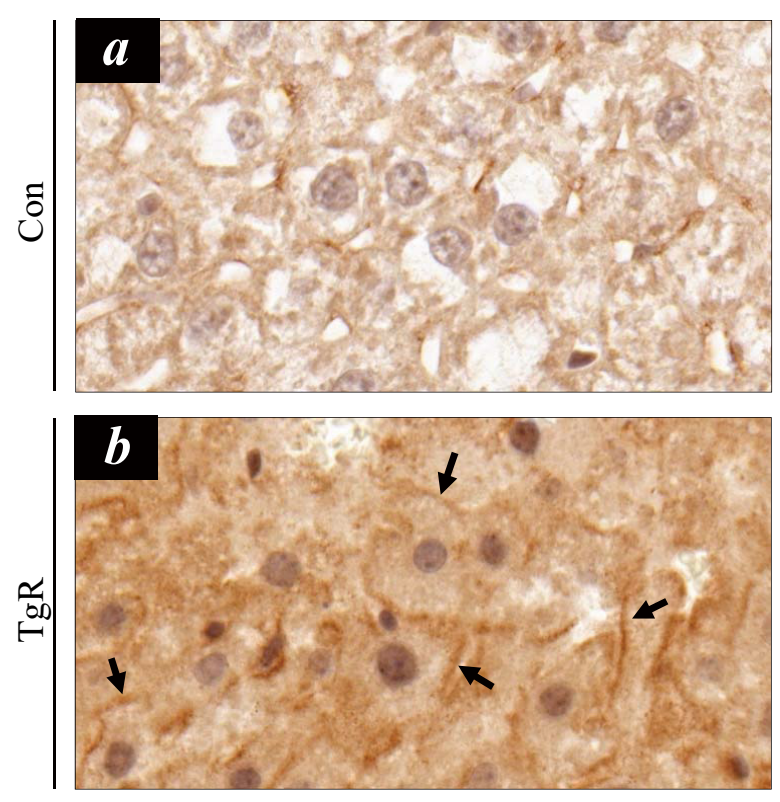

Fig. 4. Immunocytochemical localization of STAMP2 in hepatic tissues after feeding diabetic mice TRSPF for 4 weeks. Hepatic tissues were fixed, paraffin-embedded, and immunostained with STAMP2 antibody, and observed under a digital slide scanning system. Arrows indicate intense immune-positive staining for STAMP2 in the membrane or boundary of hepatocytes. Original magnification: 400x. STAMP2, six-transmembrane protein of prostate 2; TR, transgenic rice; SPF, silk protein fibroin.

steatosis in diabetic mice will be understood with greater clarity upon further biochemical and molecular studies in cellular models.

\section{REFERENCES}

Altman GH, Diaz F, Jakuba C, Calabro T, Horan RL, Chen J, Lu H, Richmond J, Kaplan DL (2003). Silk-based biomaterials. Biomaterials 24:401-416.

Cheng R, Qiu J, Zhou XY, Chen XH, Zhu C, Qin DN, Wang JW, Ni YH, Ji CB, Guo XR (2011) Knockdown of STEAP4 inhibits insulin-stimulated glucose transport and GLUT4 translocation via attenuated phosphorylation of Akt, independent of the effects of EEA1. Mol Med Rep 4:519-523.

Deacon CF (2019) Physiology and pharmacology of DPP-4 in glucose homeostasis and the treatment of type 2 diabetes. Front Endocrinol (Lausanne) 10:80.

Do SG, Park JH, Nam H, Kim JB, Lee JY, Oh YS, Suh JG (2012) Silk fibroin hydrolysate exerts an anti-diabetic effect by increasing pancreatic $\beta$ cell mass in C57BL/KsJ-db/db mice.J Vet Sci 13:339-344.

Freeman AM, Pennings N (2020) Insulin Resistance. In: StatPearls. StatPearls, Treasure Island, FL.

Gotoh K, Izumi H, Kanamoto T, Tamada Y, Nakashima H (2000) Sulfated fibroin, a novel sulfated peptide derived from silk, inhibits human immunodeficiency virus replication in vitro. Biosci Biotechnol Biochem 64:1664-1670.

Hawley SA, Gadalla AE, Olsen GS, Hardie DG (2002) The antidiabetic drug metformin activates the AMP-activated protein kinase cascade via an adenine nucleotide-independent mechanism. Diabetes 51:2420-2425. 
Hyun CK, Kim IY, Frost SC (2004) Soluble fibroin enhances insulin sensitivity and glucose metabolism in 3T3-L1 adipocytes. J Nutr 134:3257-3263.

Igarashi K, Yoshioka K, Mizutani K, Miyakoshi M, Murakami T, Akizawa T (2006) Blood pressure-depressing activity of a peptide derived from silkworm fibroin in spontaneously hypertensive rats. Biosci Biotechnol Biochem 70:517-520.

Jung EY, Lee HS, Lee HJ, Kim JM, Lee KW, Suh HJ (2010) Feeding silk protein hydrolysates to C57BL/KsJ-db/db mice improves blood glucose and lipid profiles. Nutr Res 30:783-790.

Kim HY, Park SY, Lee MH, Rho JH, Oh YJ, Jung HU, Yoo SH, Jeong NY, Lee HJ, Suh S, Seo SY, Cheong J, Jeong JS, Yoo YH (2015) Hepatic STAMP2 alleviates high fat diet-induced hepatic steatosis and insulin resistance.J Hepatol 63:477-485.

Kluge JA, Rabotyagova O, Leisk GG, Kaplan DL (2008) Spider silks and their applications. Trends Biotechnol 26:244-251.

Korkmaz CG, Korkmaz KS, Kurys P, Elbi C, Wang L, Klokk TI, Hammarstrom C, Troen G, Svindland A, Hager GL, Saatcioglu F (2005) Molecular cloning and characterization of STAMP2, an androgen-regulated six transmembrane protein that is overexpressed in prostate cancer. Oncogene 24:4934-4945.

Lebovitz HE (2001) Insulin resistance: Definition and consequences. Exp Clin Endocrinol Diabetes 109:S135-S148.

Lee KS, Kim BY, Kim DH, Jin BR (2012) Molecular cloning and characterization of the partial major ampullate silk protein gene from the spider Araneus ventricosus. J Asia Pac Entomol 15:641-646.

Lee KS, Kim BY, Kim DH, Jin BR (2014) Spider silk fibroin enhances insulin secretion and reduces blood glucose levels in diabetic mice.J Asia-Pacific Entomol 19:907-909.

Lee KS, Kim BY, Kim DH, Jin BR (2016) Recombinant spider silk fibroin protein produces a noncytotoxic and non-inflammatory response.J Asia-Pacific Entomol 17:1015-1018.

Mohanty A, Sarma NP, Tyagi AK (1999) Agrobacterium-mediated high frequency transformation of an elite indica rice variety Pusa Basmati 1 and transmission of the transgenes to R2 progeny. Plant Sci 147:127-137.

Park JE, Jeong YJ, Park JB, Kim HY, Yoo YH, Lee KS, Yang WT, Kim DH, Kim JM (2019) Dietary exposure to transgenic rice expressing the spider silk protein fibroin reduces blood glucose levels in diabetic mice: The potential role of insulin receptor substrate-1 phosphorylation in adipocytes. Dev Reprod 23:223-229.

Park KJ, Jin HH, Hyun CK (2002) Antigenotoxicity of peptides produced from silk fibroin. Process Biochem 38:411-418.

Park S, Zhang T, Qiu JY, Wu X, Lee JY, Lee BY (2020) Acid hydrolyzed silk peptide consumption improves anti-diabetic symptoms by potentiating insulin secretion and preventing gut microbiome dysbiosis in non-obese type 2 diabetic animals. Nutrients 12:311.

Park SY, Kim B, Lee YK, Lee S, Chun JM, Suh JG, Park JH (2020) Silk fibroin promotes the regeneration of pancreatic $\beta$-cells in the C57BL/KsJ-Lepr ${ }^{d b / d}$ mouse. Molecules 25:3259.

Qin DN, Zhu JG, Ji CB, Chunmei-Shi, Kou CZ, Zhu GZ, Zhang CM, Wang YP, Ni YH, Guo XR (2011). Monoclonal antibody to six transmembrane epithelial antigen of prostate- 4 influences insulin sensitivity by attenuating phosphorylation of P13K (P85) and Akt: Possible mitochondrial mechanism.J Bioenerg Biomembr 43:247-255.

Rena G, Hardie DG, Pearson ER (2017) The mechanisms of action of metformin. Diabetologia 60:1577-1585.

Sanchez-Rangel E, Inzucchi SE (2017) Metformin: Clinical use in type 2 diabetes. Diabetologia 60:1586-1593. 
Shaw RJ, Lamia KA, Vasquez D, Koo SH, Bardeesy N, Depinho RA, Montminy M, Cantley LC (2005) The kinase LKB1 mediates glucose homeostasis in liver and therapeutic effects of metformin. Science 310:1642-1646.

Sikkeland J, Saatcioglu F (2013) Differential expression and function of stamp family proteins in adipocyte differentiation. PLoS One 8:e68249.

Song YM, Lee YH, Kim JW, Ham DS, Kang ES, Cha BS, Lee HC, Lee BW (2015) Metformin alleviates hepatosteatosis by restoring SIRT1-mediated autophagy induction via an AMPactivated protein kinase-independent pathway. Autophagy 11:46-59.

Thomas CC, Philipson LH (2015) Update on diabetes classification. Med Clin North Am 99:116.

Toki S (1997) Rapid and efficient agrobacterium-mediated transformation in rice. Plant Mol Bio Rep 15:16-21.

Wellen KE, Fucho R, Gregor MF, Furuhashi M, Morgan C, Lindstad T, Vaillancourt E, Gorgun CZ, Saatcioglu F, Hotamisligil GS (2007) Coordinated regulation of nutrient and inflammatory responses by STAMP2 is essential for metabolic homeostasis. Cell 129:537-548.

Woo SL, Xu H, Li H, Zhao Y, Hu X, Zhao J, Guo X, Guo T, Botchlett R, Qi T (2014) Metformin ameliorates hepatic steatosis and inflammation without altering adipose phenotype in dietinduced obesity. PLoS One 9:e91111. 
